From the College of Medicine, Mayo Clinic, Rochester, MN; the College of Medicine, University of lowa, IA City, IA; and the University of Rochester, Rochester, NY.

Submitted February 12, 2010; accepted May 28, 2010; published online ahead of print at www.jco.org on August 16, 2010

Supported in part by Grant No. P50 CA97274 from the National Institutes of Health and the Mayo Hematologic Malignancies Fund.

Authors' disclosures of potential conflicts of interest and author contributions are found at the end of this article.

Corresponding author: James R. Cerhan, MD, PhD, Division of Epidemiology, College of Medicine, Mayo Clinic, 200 1st ST SW, Rochester, MN 55905; e-mail: cerhan.james@mayo.edu.

(C) 2010 by American Society of Clinical Oncology

0732-183X/10/2827-4191/\$20.00

DOI: 10.1200/JCO.2010.28.6674

\title{
Vitamin D Insufficiency and Prognosis in Non-Hodgkin's Lymphoma
}

Matthew T. Drake, Matthew J. Maurer, Brian K. Link, Thomas M. Habermann, Stephen M. Ansell, Ivana N. Micallef, Jennifer L. Kelly, William R. Macon, Grzegorz S. Nowakowski, David J. Inwards, Patrick B. Johnston, Ravinder J. Singh, Cristine Allmer, Susan L. Slager, George J. Weiner, Thomas E. Witzig, and James R. Cerhan

See accompaning articles on pages 4184, 4199, and 4207

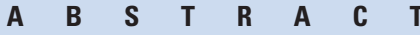

\section{Purpose}

Vitamin D insufficiency is common in the United States, with low levels linked in some studies to higher cancer incidence, including non-Hodgkin's lymphoma (NHL). Recent data also suggest that vitamin $\mathrm{D}$ insufficiency is related to inferior prognosis in some cancers, although there are no data for $\mathrm{NHL}$.

\section{Patients and Methods}

We tested the hypothesis that circulating 25-hydroxyvitamin D [25(OH)D] levels are predictive of event-free survival (EFS) and overall survival (OS) in a prospective cohort of 983 newly diagnosed patients with $\mathrm{NHL}$. 25(OH)D and 1,25-dihydroxyvitamin $\mathrm{D}\left[1,25(\mathrm{OH})_{2} \mathrm{D}\right]$ levels were measured by liquid chromatography-tandem mass spectrometry.

\section{Results}

Mean age at diagnosis was 62 years (range, 19 to 94 years); 44\% of patients had insufficient $25(\mathrm{OH}) \mathrm{D}$ levels $(<25 \mathrm{ng} / \mathrm{mL})$ within 120 days of diagnosis. Median follow-up was 34.8 months; 404 events and 193 deaths (168 from lymphoma) occurred. After adjusting for known prognostic factors and treatment, 25(OH)D insufficient patients with diffuse large B-cell lymphoma (DLBCL) had inferior EFS (hazard ratio [HR], $1.41 ; 95 \% \mathrm{Cl}, 0.98$ to 2.04 ) and $\mathrm{OS}(\mathrm{HR}, 1.99 ; 95 \% \mathrm{Cl}, 1.27$ to 3.13); 25(OH)D insufficient patients with T-cell lymphoma also had inferior EFS (HR, 1.94; $95 \% \mathrm{Cl}$, 1.04 to 3.61) and $\mathrm{OS}(\mathrm{HR}, 2.38 ; 95 \% \mathrm{Cl}, 1.04$ to 5.41). There were no associations with EFS for the other NHL subtypes. Among patients with DLBCL and T-cell lymphoma, higher $1,25(\mathrm{OH})_{2} \mathrm{D}$ levels were associated with better EFS and OS, suggesting that any putative tumor $1-\alpha^{-}$ hydroxylase activity did not explain the 25(OH)D associations.

\section{Conclusion}

25(OH)D insufficiency was associated with inferior EFS and OS in DLBCL and T-cell lymphoma. Whether normalizing vitamin $\mathrm{D}$ levels in these patients improves outcomes will require testing in future trials.

\section{J Clin Oncol 28:4191-4198. (C) 2010 by American Society of Clinical Oncology}

\section{INTRODUCTION}

Vitamin D insufficiency is common in the United States. Multiple studies have demonstrated that $25 \%$ to $50 \%$ of patients seen in clinical practice have vitamin D levels below the optimal range. ${ }^{1-3}$ Vitamin $\mathrm{D}$ is obtained either from skin exposure to ultraviolet $\mathrm{B}$ radiation in the form of sunlight, or through dietary sources including supplementation. Serum levels of 25-hydroxyvitamin D [25(OH)D] reflect whole body vitamin $\mathrm{D}$ stores, and are used to assess individual adequacy or insufficiency. $25(\mathrm{OH}) \mathrm{D}$ is converted to 1,25 -dihydroxyvitamin $\mathrm{D}\left[1,25(\mathrm{OH})_{2} \mathrm{D}\right]$, considered the physiologically active form of vita- min $\mathrm{D}$, via the action of $1-\alpha$-hydroxylase. While much of this conversion occurs in the kidney, multiple other tissues (including lymphoma tumor cells) also have 1- $\alpha$-hydroxylase activity, and can thus regulate $1,25(\mathrm{OH})_{2} \mathrm{D}$ levels at the local tissue level. Once formed, $1,25(\mathrm{OH})_{2} \mathrm{D}$ exerts its effects through binding to the vitamin $\mathrm{D}$ nuclear transcription factor receptor, where it may regulate the expression of nearly 200 genes. $^{4}$

Although the central role of vitamin D in maintaining serum calcium and skeletal homeostasis has long been appreciated, much recent work has demonstrated that vitamin $\mathrm{D}$ also has pleiotropic effects on cellular differentiation, proliferation, apoptosis, 
and angiogenesis. ${ }^{5}$ Intriguingly, several reports now suggest low serum $25(\mathrm{OH}) \mathrm{D}$ levels may be associated with increased cancer incidence. At present, the strongest data for an inverse association between circulating vitamin D levels and malignancy exists for studies that have examined patients with colorectal ${ }^{6,7}$ and breast ${ }^{8,9}$ cancer. While there is little evidence from case-control studies that dietary intake of vitamin D is associated with non-Hodgkin's lymphoma (NHL) risk, ${ }^{10}$ a pooled analysis of 10 such studies found that higher levels of recreational sun exposure were associated with lower risk of NHL. ${ }^{11}$ Furthermore, data from two prospective cohort studies $^{12,13}$ provide suggestive evidence that low serum $25(\mathrm{OH}) \mathrm{D}$ levels are associated with increased risk of NHL incidence.

In addition to risk of developing malignancy, there are recent data that suggest low 25(OH)D levels at diagnosis may be associated with poorer prognosis in colorectal ${ }^{14}$ and breast ${ }^{15}$ cancer, as well as multiple myeloma. ${ }^{16}$ To our knowledge, however, there are no data on NHL prognosis except for a small study of 24 patients which reported that alfacalcidol (a synthetic analog of $1,25(\mathrm{OH})_{2} \mathrm{D}$ ) induced regression in follicular, small cleaved cell lymphoma. ${ }^{17}$ To test the hypothesis that vitamin D levels are predictive of event-free and overall survival in patients with newly diagnosed NHL, we examined the prognostic effects of circulating 25(OH)D levels in a prospective cohort of consecutively enrolled patients with newly diagnosed NHL.

\section{PATIENTS AND METHODS}

\section{Study Population}

This study was reviewed and approved by the human subjects institutional review board at the Mayo Clinic and the University of Iowa, and written informed consent was obtained from all participants. All subjects in this analysis were from the Molecular Epidemiology Resource of the University of Iowa/Mayo Clinic Lymphoma Specialized Program of Research Excellence. ${ }^{18}$ Since September 2002, we offered enrollment to consecutive, newly diagnosed patients with NHL (within 9 months) who were evaluated at Mayo Clinic Rochester and the University of Iowa, were age 18 years or older, and were a resident of the United States. Exclusion criteria included known HIV infection and unwillingness or inability to provide written informed consent.

All pathology was reviewed by a lymphoma hematopathologist to verify the diagnosis and to classify each case according to the WHO classification. ${ }^{19}$ We grouped the subtypes for analysis into diffuse large B-cell (DLBCL), mantle cell lymphoma (MCL), follicular lymphoma (FL), post-FL (consisting of marginal zone and lymphoplasmacytic lymphoma), and T-cell lymphoma (TCL; consisting of peripheral TCL, anaplastic large cell lymphoma, cutaneous TCL, and TCL not otherwise specified [NOS]), as well as all other NHL.

Baseline clinical, laboratory, and treatment data were abstracted from medical records using a standard protocol. Participants provided a peripheral blood sample for serum and DNA banking. Timing of the sample collection with respect to treatment (ie, pretreatment, during treatment, or posttreatment) was recorded. All patients were systematically observed every 6 months for the first 3 years, and then annually thereafter. Disease progression, retreatment, and deaths were verified through medical record review. We also verified patients' reports of no disease progression on an annual basis against their physician's report. For decedents, we obtained a copy of the death certificate as well as medical records associated with death. Study physicians assigned a cause of death using definitions developed for the Eastern Cooperative Oncology Group (ECOG) Intergroup trial $4494 .^{20}$

\section{Vitamin D Measurements}

We defined vitamin D insufficiency as a serum 25(OH)D level lower than $25 \mathrm{ng} / \mathrm{mL}$ ( $62.5 \mathrm{nmol} / \mathrm{L})$. Although consensus guidelines for the diagnosis of vitamin D insufficiency have not been established, this is an accepted level for the establishment of hypovitaminosis $\mathrm{D}$, and is the current threshold used
Table 1. Demographic and Clinical Correlates of Vitamin D Levels and Prevalence of 25-Hydroxyvitamin D Insufficiency

\begin{tabular}{|c|c|c|c|c|c|c|}
\hline \multirow[b]{2}{*}{ Covariate } & \multirow[b]{2}{*}{ No. } & \multicolumn{2}{|c|}{$\begin{array}{c}25- \\
\text { Hydroxyvitamin } \\
\text { D Levels } \\
\text { (ng/mL) }\end{array}$} & \multicolumn{3}{|c|}{$\begin{array}{l}\text { 25-Hydroxyvitamin D } \\
\text { Insufficient }\end{array}$} \\
\hline & & Mean & SD & No. & $\%$ & $P^{*}$ \\
\hline \multicolumn{7}{|l|}{$\begin{array}{l}\text { Timing of serum draw, } \\
<120 \text { days of } \\
\text { diagnosis }\end{array}$} \\
\hline Pretreatment & 649 & 27.4 & 10.4 & 265 & 40.8 & .002 \\
\hline $\begin{array}{l}\text { During or post- } \\
\text { treatment }\end{array}$ & 334 & 24.8 & 11.1 & 171 & 51.4 & \\
\hline \multicolumn{7}{|l|}{ Sex } \\
\hline Male & 540 & 26.3 & 10.2 & 242 & 44.8 & .75 \\
\hline Female & 443 & 26.7 & 11.3 & 194 & 43.8 & \\
\hline \multicolumn{7}{|l|}{ Age, years } \\
\hline$\leq 60$ & 458 & 26.4 & 10.7 & 204 & 44.5 & .91 \\
\hline $61+$ & 525 & 26.5 & 10.8 & 232 & 44.2 & \\
\hline \multicolumn{7}{|l|}{ Residence at diagnosis } \\
\hline$M N, I A, I L, W I, N D, S D$ & 874 & 26.2 & 10.6 & 399 & 45.7 & .02 \\
\hline Outside six-state region & 109 & 29.0 & 11.3 & 37 & 33.9 & \\
\hline \multicolumn{7}{|l|}{ Month of diagnosis } \\
\hline March-May & 212 & 25.0 & 10.1 & 110 & 51.9 & .02 \\
\hline June-August & 249 & 28.3 & 10.1 & 94 & 37.8 & \\
\hline September-November & 265 & 27.0 & 11.5 & 114 & 43.0 & \\
\hline December-February & 257 & 25.5 & 10.8 & 118 & 45.9 & \\
\hline \multicolumn{7}{|l|}{ Performance status } \\
\hline 0 or 1 & 845 & 27.7 & 10.3 & 336 & 39.8 & $<.001$ \\
\hline$>1$ & 137 & 18.8 & 10.3 & 100 & 73.0 & \\
\hline \multicolumn{7}{|l|}{ Subtypet } \\
\hline DLBCL & 370 & 24.7 & 10.7 & 192 & 51.9 & .02 \\
\hline $\mathrm{TCL}$ & 70 & 23.2 & 11.8 & 40 & 57.1 & \\
\hline $\mathrm{MCL}$ & 71 & 27.0 & 9.1 & 26 & 36.6 & \\
\hline $\mathrm{FL}$ & 285 & 28.2 & 10.3 & 110 & 38.6 & \\
\hline Post-FL & 109 & 28.8 & 11.0 & 41 & 37.6 & \\
\hline All other & 78 & 28.1 & 10.5 & 27 & 34.6 & \\
\hline \multicolumn{7}{|l|}{ IPI for DLBCL only } \\
\hline $0-1$ & 135 & 25.9 & 9.7 & 62 & 45.9 & .07 \\
\hline 2 & 97 & 25.6 & 11.0 & 50 & 51.6 & \\
\hline 3 & 81 & 24.9 & 11.2 & 42 & 51.9 & \\
\hline 4 or 5 & 57 & 19.9 & 10.7 & 38 & 66.7 & \\
\hline \multicolumn{7}{|l|}{ IPI for TCL only } \\
\hline $0-1$ & 23 & 30.2 & 10.7 & 9 & 39.1 & .17 \\
\hline 2 & 18 & 20.5 & 10.5 & 11 & 61.1 & \\
\hline 3 & 14 & 19.9 & 10.3 & 9 & 64.3 & \\
\hline 4 or 5 & 15 & 18.9 & 12.5 & 11 & 73.3 & \\
\hline \multicolumn{7}{|l|}{ FLIPI for FL only } \\
\hline $0-1$ & 127 & 28.5 & 10.2 & 48 & 37.8 & .03 \\
\hline 2 & 88 & 27.7 & 10.9 & 38 & 43.2 & \\
\hline 3 & 50 & 30.3 & 9.5 & 12 & 24.0 & \\
\hline $4-5$ & 20 & 23.7 & 9.5 & 12 & 60.0 & \\
\hline \multicolumn{7}{|l|}{ MIPI for MCL only } \\
\hline 0-3 (low risk) & 58 & 27.7 & 8.5 & 18 & 31.0 & .04 \\
\hline 4-12 (interm/high risk) & 13 & 23.9 & 11.2 & 8 & 61.5 & \\
\hline
\end{tabular}

Abbreviations: DLBCL, diffuse large B-cell lymphoma; TCL, T-cell lymphoma; MCL, mantle cell lymphoma; FL, follicular lymphoma; IPI, International Prognostic Index; FLIPI, Follicular Lymphoma International Prognostic Index; MIPI, Mantle Cell International Prognostic Index; PTCL, peripheral T-cell lymphoma; NOS, not otherwise specified; CTCL, cutaneous T-cell lymphoma; $A L C L$, anaplastic largecell lymphoma; MZL, marginal-zone lymphoma; LPL, lymphoplasmacytic lymphoma; NHL, non-Hodgkin's lymphoma; BL, Burtkitt's lymphoma.

* $P$ value from $\chi^{2}$ test of vitamin $D$ sufficient $v$ insufficient.

†TCL includes PTCL NOS ( $n=25), \operatorname{CTCL}(n=9), \operatorname{ALCL}(n=7)$, and miscellaneous ( $n=29$ ); Post-FL includes splenic MZL $(n=13)$, extranodal MZL $(n=73)$, nodal MZL $(n=6)$, and $\mathrm{LPL}(n=17)$; and other $\mathrm{NHL}$ includes $\mathrm{BL}(\mathrm{n}=8)$, composite NHL $(n=10)$, other B-cell NOS $(n=51)$, and miscellaneous $(n=9)$. 
by Mayo Medical Laboratories (http://www.mayomedicallaboratories.com). In order to avoid assay variability, which can significantly confound vitamin D determinations made using radioimmunoassay methods, ${ }^{21}$ all vitamin $D$ measurements were made by liquid chromatography-tandem mass spectrometry (LC-MS/MS). A single vitamin D measurement has been shown to be highly reproducible..$^{22,23}$

Measurements of $25(\mathrm{OH}) \mathrm{D}$ were made by deuterated stable isotope $\left[\mathrm{d}_{6}-25(\mathrm{OH}) \mathrm{D}\right]$-dilution LC-MS/MS on an API 4000 instrument (Applied Biosystems, Forest City, CA), with sample introduction performed by a cohesive four-channel multiplexed system (Thermo-Fisher, Waltham, MA). Calibration utilized a 6-point standard curve over a concentration range of 0 to 200 $\mathrm{ng} / \mathrm{mL}$. Each subject's total $25(\mathrm{OH}) \mathrm{D}$ was assessed as the additive sum of the $25(\mathrm{OH}) \mathrm{D}_{2}$ and $25(\mathrm{OH}) \mathrm{D}_{3}$ components. Intra- and interassay coefficients of variation were all lower than 7\% (Appendix Table A1, online only). All 983 samples were successfully assayed. For patients with DLBCL and TCL, we also measured $1,25(\mathrm{OH})_{2} \mathrm{D}$, which was the sum of each subject's $1,25(\mathrm{OH})_{2} \mathrm{D}_{2}$ and $1,25(\mathrm{OH})_{2} \mathrm{D}_{3}$ as determined by isotope-dilution LC-MS/MS on an API 5000 instrument (Applied Biosystems) using deuterated internal standards for each analyte. Intra- and interassay coefficients of variation are reported in Appendix Table A1.

\section{Statistical Analysis}

$\chi^{2}$ and Fisher's exact tests, where appropriate, were used to assess the association of 25(OH)D insufficiency and clinical and demographic factors. All survival analyses were analyzed within the following grouped subtypes: DLBCL, FL, post-FL, MCL, TCL, and all other NHL. Event-free survival (EFS) was defined as the time from diagnosis to disease progression, re-treatment, or death due to any cause. Lymphoma-specific survival (LSS) was defined as the time from diagnosis to death due to disease, and overall survival (OS) was defined as the time from diagnosis to death due to any cause. Patients without an event or death were censored at time of last known follow-up. KaplanMeier ${ }^{24}$ curves and Cox proportional hazards regression models ${ }^{25}$ were used to assess the association of vitamin D levels and outcome. Cox models were adjusted for subtype specific prognostic factors. For DLBCL, this included the International Prognostic Index (IPI) ${ }^{26}$ and treatment (defined as immunochemotherapy $v$ other); for FL, this included the FLIPI score ${ }^{27}$ and grade 3 FL; for TCL, this included the IPI ${ }^{26}$; for MCL, this included the mantle cell $\mathrm{IPI}^{28}$; for post-FL, this included stage and performance status (PS); and for all other NHL, this included stage and PS. We also analyzed the associations using the actual, continuously distributed $25(\mathrm{OH}) \mathrm{D}$ levels values via penalized smoothing splines, or P-splines. ${ }^{29}$ Briefly, this is a nonparametric modeling approach that is a generalization of polynomial splines. It allowed us to examine the unrestricted association of the $25(\mathrm{OH}) \mathrm{D}$ levels with EFS and OS, without regard to functional form. For DLBCL and TCL, we further evaluated $1,25(\mathrm{OH})_{2} \mathrm{D}$ levels (categorized into quartiles based on histology-specific distribution) with the three outcomes, overall and stratified by $25(\mathrm{OH}) \mathrm{D}$ levels (insufficient, sufficient). Analyses were performed using SAS version 9.1.3 (SAS Institute, Cary, NC) and R ( http://www.r-project.org/).

\section{RESULTS}

From September 2002 through February 2008, 1,691 patients with NHL were enrolled onto the study; this does not include chronic lymphocyte leukemia/small lymphocyte leukemia, which is being reported elsewhere. Of the 1,691 patients, 701 were excluded because they did not have a serum sample available and/or drawn within 120 days of diagnosis and seven were excluded for missing clinical or outcome data, leaving a total of 983 subjects available for analysis.

Of the 983 patients with NHL, the mean age at diagnosis was 62 years (range, 19 to 94 years) and 55\% were male. Overall, 56 patients $(5.7 \%)$ had severe insufficiency $(<10 \mathrm{ng} / \mathrm{mL}), 380$
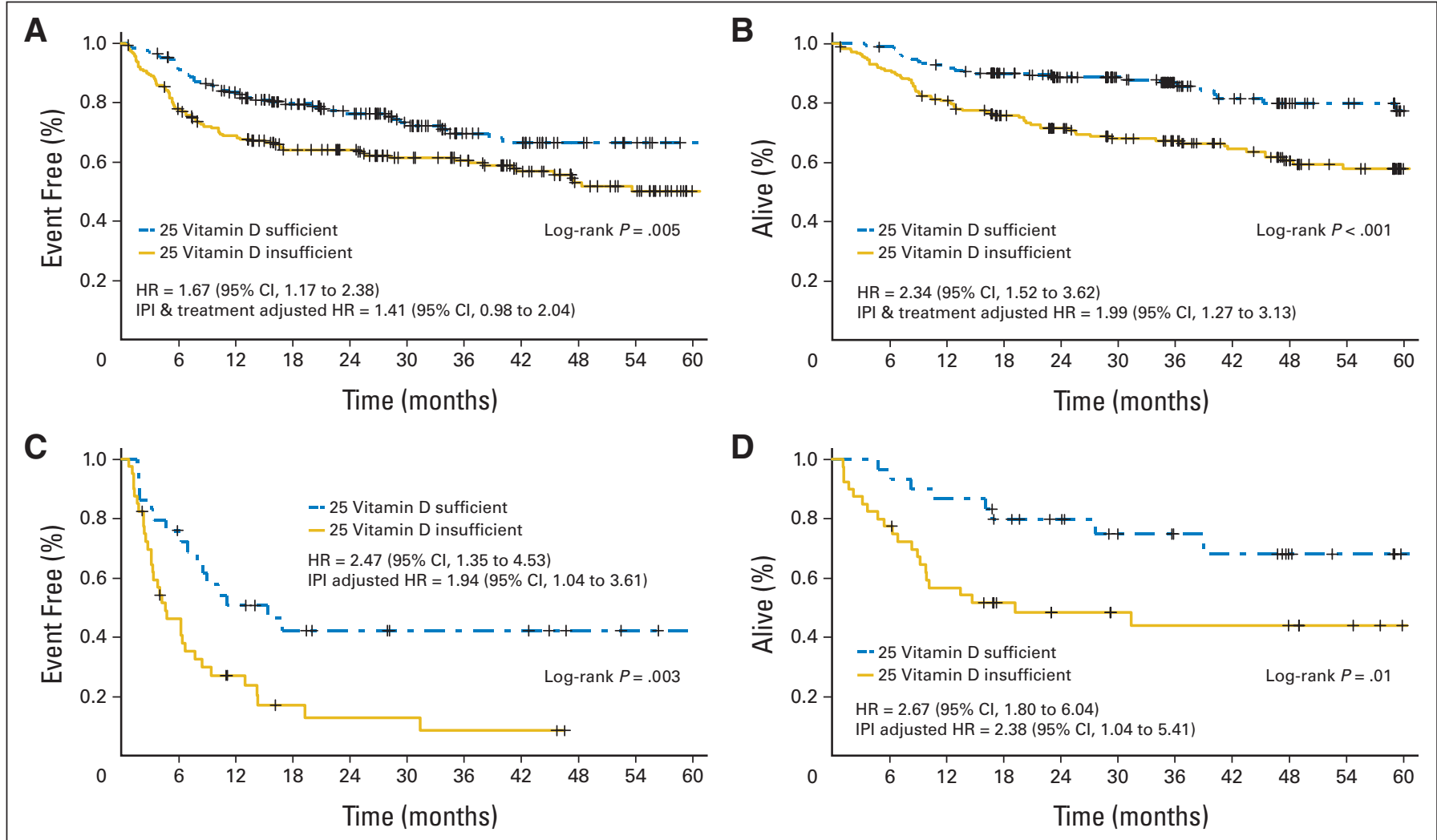

Fig 1. Kaplan-Meier curves for 25-hydroxyvitamin D deficiency and (A) diffuse large B-cell (DLBCL) event-free survival (EFS), (B) DLBCL overall survival (OS), (C) T-cell Iymphoma (TCL) EFS and (D) TCL OS. HR, hazard ratio; IPI, International Prognostic Index. 


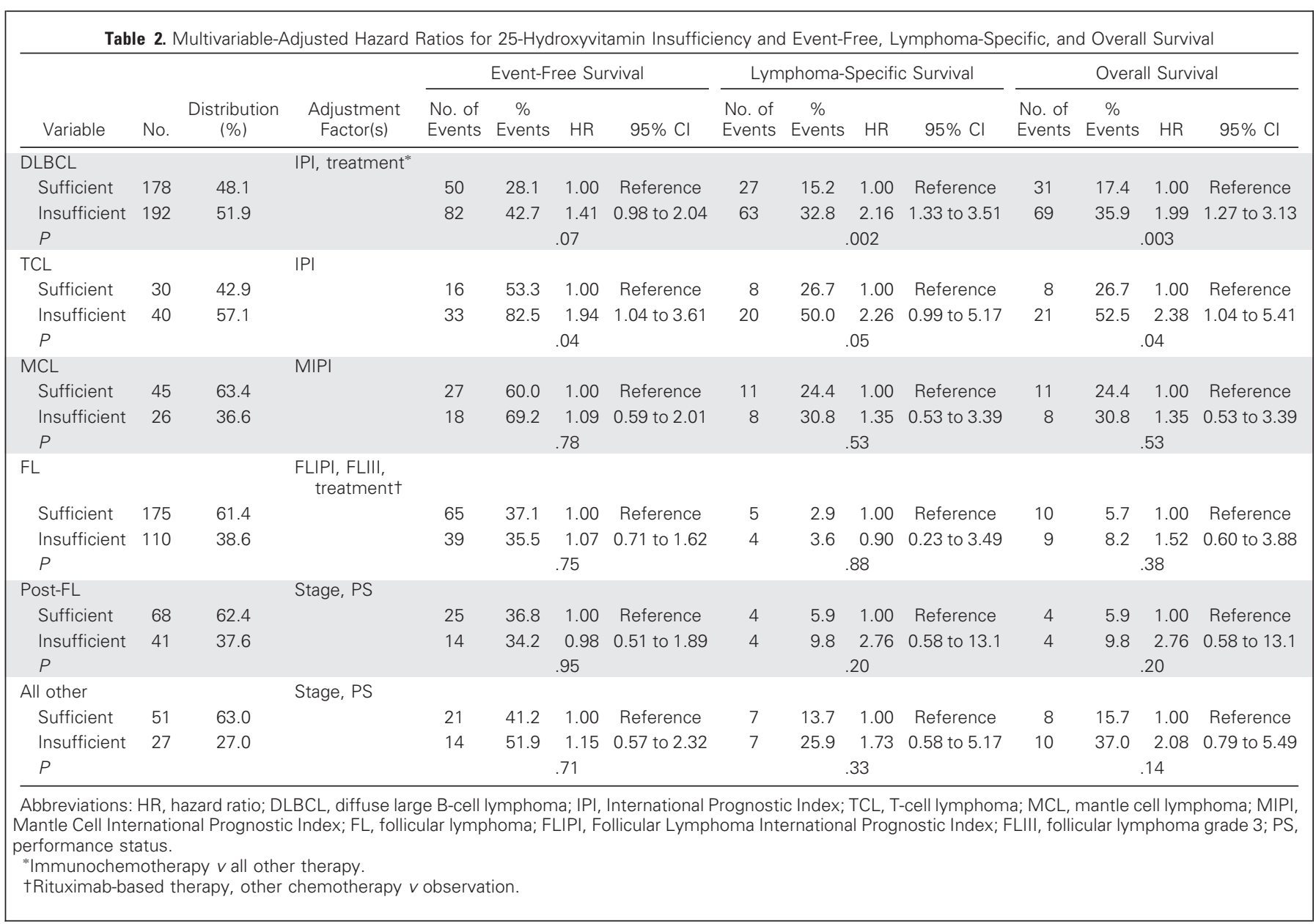

(38.7\%) had mild to moderate insufficiency ( 10 to $24 \mathrm{ng} / \mathrm{mL}$ ), and $547(55.6 \%)$ were in the optimal range (25 to $80 \mathrm{ng} / \mathrm{mL}$ ) for $25(\mathrm{OH}) \mathrm{D} ; 436(44 \%)$ were classified as $25(\mathrm{OH}) \mathrm{D}$ insufficient (combination of severe and mild to moderate insufficiency). $25(\mathrm{OH}) \mathrm{D}$ insufficiency was not correlated with age or sex, but was positively correlated with having a serum drawn during or posttreatment; residence in the six state region of the upper Midwest; diagnosis from March through May; PS higher than 1; and DLBCL or TCL subtypes (Table 1). Subtype-specific prognostic indices were also positively correlated with $25(\mathrm{OH}) \mathrm{D}$ insufficiency (Table 1 ), and this was most strongly driven by performance status within each of the subtypes (Appendix Table A2, online only). Disease stage was not correlated with $25(\mathrm{OH}) \mathrm{D}$ insufficiency for DLBCL, $\mathrm{FL}$, or post-FL, but higher disease stage was correlated with 25( $\mathrm{OH}) \mathrm{D}$ insufficiency in TCL (Appendix Table A2).

During a median follow-up of 34.8 months (range, 0.5 to 77 months), there were 404 events and 193 deaths, of which 168 were attributed to lymphoma. For DLBCL, $52 \%$ of the patients were 25(OH)D insufficient, and as shown in Figure 1, insufficient patients had inferior EFS (log-rank $P=.005)$ and OS (log-rank $P<.001$ ); details on univariate HRs for all outcomes are available in Appendix Table A3 (online only). After adjusting for the IPI and treatment (Table 2), 25(OH)D insufficient patients continued to have inferior EFS (HR, 1.41; 95\% CI, 0.98 to 2.04), LSS (HR, 2.16; 95\% CI, 1.33 to $3.51)$ and $\mathrm{OS}(\mathrm{HR}, 1.99 ; 95 \% \mathrm{CI}, 1.27$ to 3.13$)$. The association of
25(OH)D levels with EFS (Fig 2A) and OS (Fig 2B) was mainly observed over the range of 15 to $25 \mathrm{ng} / \mathrm{mL}$, and was relatively flat above $30 \mathrm{ng} / \mathrm{mL}$.

For TCL (which included PTCL and CTCL, see Table 1 for details), $57 \%$ of the patients were $25(\mathrm{OH}) \mathrm{D}$ insufficient, and insufficient patients had inferior EFS (log-rank $P=.003$ ) and OS ( $\log$-rank $P=.01)$. After adjustment for IPI (Table 2), 25(OH)D insufficient patients continued to have inferior EFS (HR, 1.94; 95\% CI, 1.04 to 3.61), LSS (HR, 2.26; 95\% CI, 0.99 to 5.17) and OS (HR, 2.38; 95\% CI, 1.04 to 5.41). Inferior EFS (Fig 2C) and OS (Fig 2D) was observed among TCL patients in both the insufficient $(<25$ $\mathrm{ng} / \mathrm{mL}$ ) and the lower end of the optimal range ( 25 to $80 \mathrm{ng} / \mathrm{mL}$ ) of 25 $(\mathrm{OH}) \mathrm{D}$ levels.

The prevalence of $25(\mathrm{OH}) \mathrm{D}$ insufficiency for the remaining subtypes in Table 2 ranged from $27 \%$ to $39 \%$, and there were no associations of $25(\mathrm{OH}) \mathrm{D}$ insufficiency with EFS. However, with the exception of LSS in FL, HRs for LSS and OS for the remaining subtypes were all above 1 , although the confidence intervals were wide, reflecting the small number of deaths in these subtypes.

Further adjustment of results in Table 1 for season of diagnosis or residence in the upper six Midwest states did not materially alter the associations ( $<10 \%$ change in HRs) reported in Table 2 (data not shown).

All serum samples tested were drawn within 120 days of diagnosis, and from a physiologic perspective we would expect little 


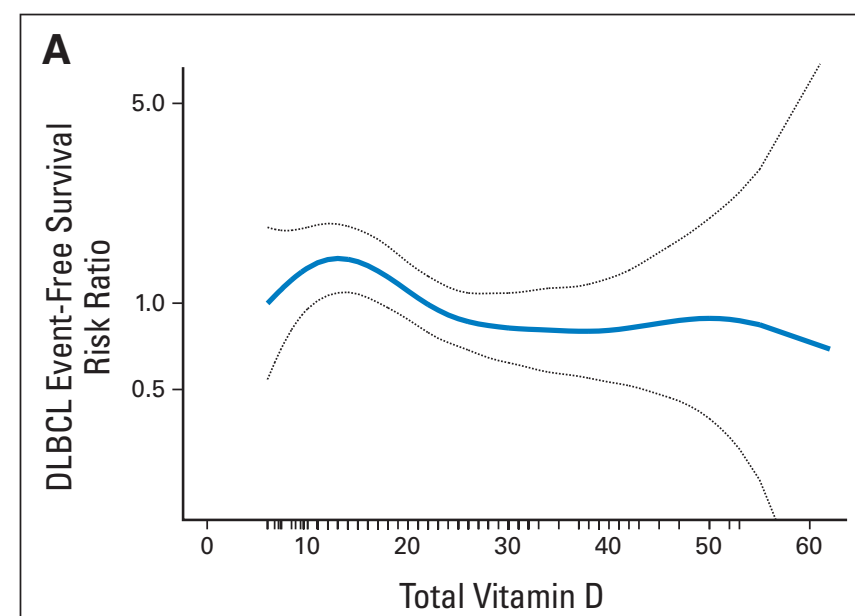

B

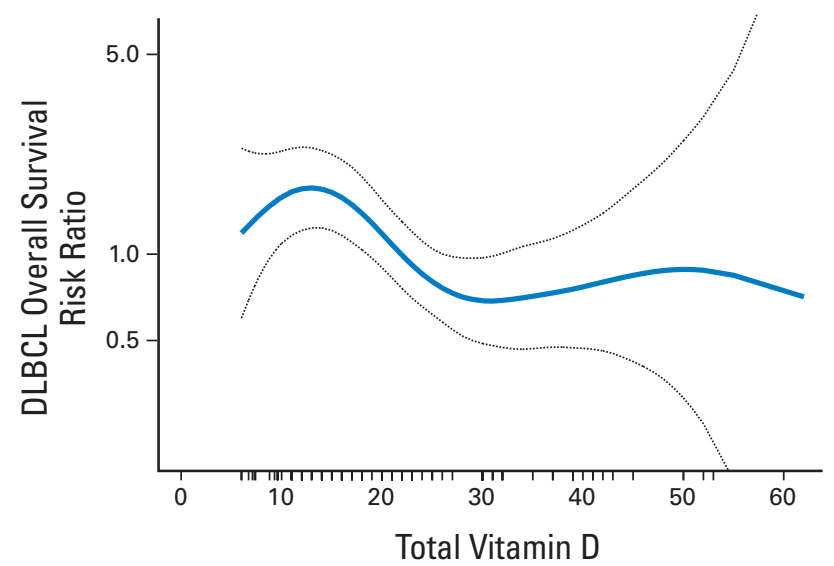

D

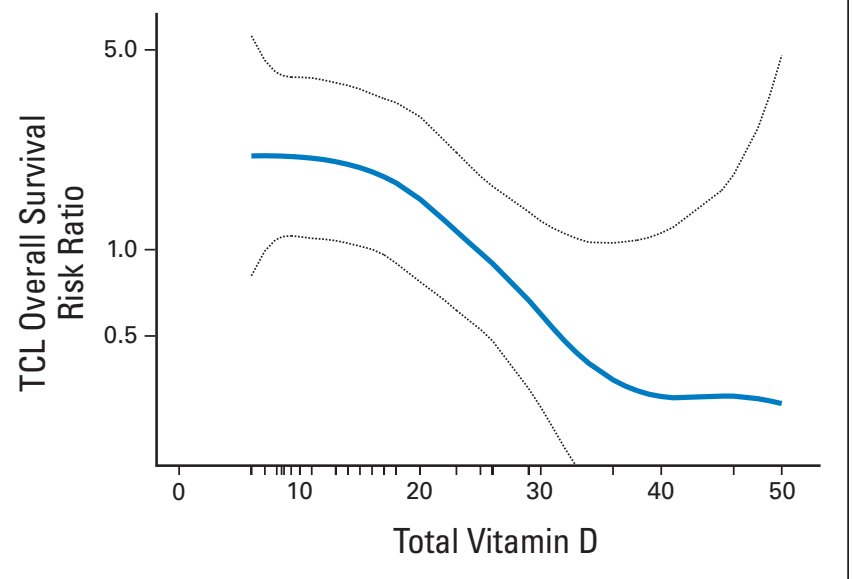

Fig 2. Estimated hazard ratios (solid line) and $95 \% \mathrm{Cl}$ (dotted lines) from multivariate models for 25-hydroxyvitamin $\mathrm{D}$ level (ng/mL) and (A) diffuse large $B$-cell (DLBCL) event-free survival, (B) DLBCL overall survival, (C) T-cell lymphoma (TCL) event-free survival, and (D) TCL overall survival.

change of $25(\mathrm{OH}) \mathrm{D}$ levels from chemotherapy over this short interval. Nevertheless, $34 \%$ of samples were drawn during or after initial therapy, and mean $25(\mathrm{OH}) \mathrm{D}$ levels and the prevalence of $25(\mathrm{OH}) \mathrm{D}$ insufficiency were modestly associated with timing of blood draw overall (Table 1). This overall association varied by subtype, and was seen only for TCL, MCL, and all other NHL, but not for DLBCL, FL, and post-FL (Appendix Table A2). Adjustment for timing of serum draw did not materially alter the associations in Table 2 (data not shown). Further, when restricted to pretreatment serum samples (Appendix Table A4, online only), our basic findings held, although the CIs around the point estimates became unstable due to small numbers for subset analyses in the lymphoma subtypes.

One potential interpretation of the association of low $25(\mathrm{OH}) \mathrm{D}$ levels with inferior DLBCL and TCL prognosis is that patients with a larger tumor burden might have increased conversion of $25(\mathrm{OH}) \mathrm{D}$ to $1,25(\mathrm{OH})_{2} \mathrm{D}$ due to increased $1-\alpha$-hydroxylase activity from the tumor, leading to artificially low serum $25(\mathrm{OH}) \mathrm{D}$ levels. ${ }^{30}$ As such, tumor size or aggressiveness might be a confounding factor. Although adjustment for IPI should remove most of the potential confounding, residual confounding remains a concern. Calcium levels were similar between $25(\mathrm{OH}) \mathrm{D}$ sufficient and insufficient patients with DLBCL and TCL (Appendix Table A5, online only). In addition, further adjustment of the results in Table 1 for albumin-corrected-calcium (as a surrogate for tumor activity, since high 1- $\alpha$-hydroxylase activity would be expected to also increase serum calcium levels) did not materially change the DLBCL results (Appendix Table A5). The results for TCL attenuated for EFS (HR, 1.35; 95\% CI, 0.63 to 2.88) and to a lesser extent for LSS (HR, 2.00; 95\% CI, 0.74 to 5.37), while OS remained similar (HR, 2.17; 95\% CI, 0.82 to 5.76 ).

To further address this issue, we measured $1,25(\mathrm{OH})_{2} \mathrm{D}$ levels in patients with DLBCL and TCL. For DLBCL, patients in the lowest three quartiles of $1,25(\mathrm{OH})_{2} \mathrm{D}$ had inferior EFS, LSS, and OS (Fig 3 and Table 3); this association was maintained when stratified by $25(\mathrm{OH}) \mathrm{D}$ sufficient versus insufficient. For TCL, patients below the median (too few patients to use quartiles) also had inferior outcomes in a pattern similar to that seen for DLBCL, although all estimates were imprecise and not statistically significant, likely due to small subject numbers (Fig 3 and Table 3). Overall, these data do not support the hypothesis that the association of lower $25(\mathrm{OH}) \mathrm{D}$ levels with poor prognosis in DLBCL and TCL is confounded by tumor production of 1- $\alpha$-hydroxylase. Further, these data also indicate that there appears to be a direct association of lower $1,25(\mathrm{OH})_{2} \mathrm{D}$ levels with inferior outcome. 

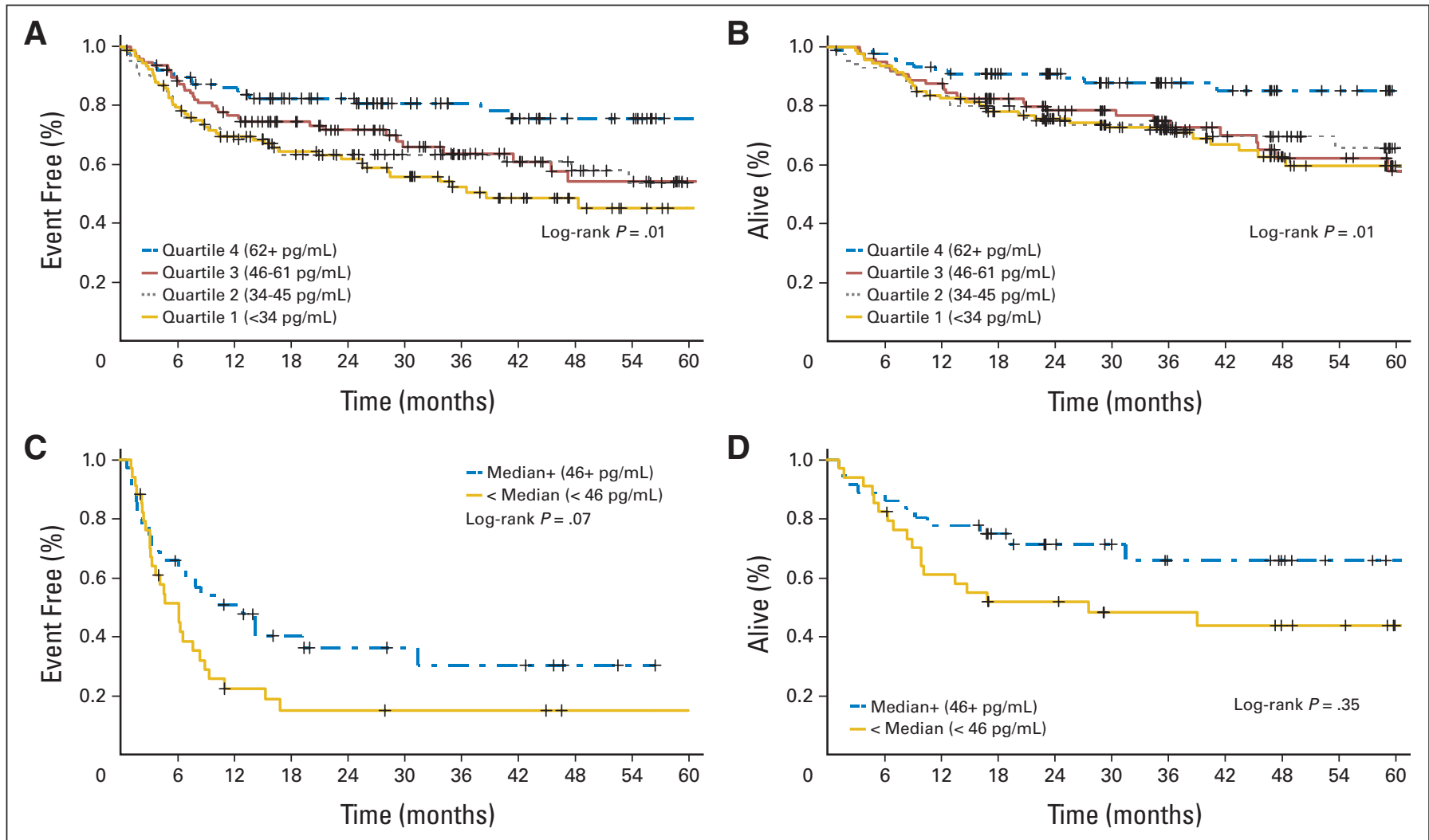

Fig 3. Kaplan-Meier curves for 1,25-dihydroxyvitamin $D$ levels and (A) diffuse large B-cell (DLBCL) event-free survival (EFS), (B) DLBCL overall survival (OS), (C) T-cell lymphoma (TCL) EFS, and (D) TCL OS. 1,25-dihydroxyvitamin D levels in $\mathrm{pg} / \mathrm{mL}$.

\section{DISCUSSION}

Over $40 \%$ of patients with NHL in this cohort had insufficient $25(\mathrm{OH}) \mathrm{D}$ levels within 120 days of diagnosis, and low levels were associated with inferior EFS, LSS, and OS for DLBCL and TCL, two of the most aggressive NHL subtypes in this study. These associations remained after adjustment for clinical factors, including IPI, timing of blood draw (pretreatment $v$ not), and season of diagnosis. While there was no association of vitamin D insufficiency and EFS for MCL, FL, post-FL or all other NHL, HRs were elevated for OS. These estimates were not statistically significant, most likely due to either the small number of patients with these types of NHL included in the cohort and/or few deaths during the relatively short follow-up time. Further studies in larger groups of patients should be performed to learn the longer-term implications of vitamin D insufficiency in these less aggressive NHL types.

Strengths of our study include the large, prospective cohort study design of consecutively enrolled patients with newly diagnosed NHL; availability of key baseline clinical and treatment data; and nearly complete follow-up of patients to define EFS, LSS, and OS. In addition, we used LC-MS/MS methods for the measurement of serum $25(\mathrm{OH}) \mathrm{D}$ and $1,25(\mathrm{OH})_{2} \mathrm{D}$ levels, a technique which is considered to be the most reliable and accurate for $25(\mathrm{OH}) \mathrm{D}$ determination. ${ }^{21}$ The major limitation of the study is the use of an observational study design, which is susceptible to confounding, although we were able to adjust for key clinical prognostic factors. Also, our study does not answer the question of whether replacing vitamin $\mathrm{D}$ would lead to a better prognosis.

Our finding that lower levels of both $25(\mathrm{OH}) \mathrm{D}$ and $1,25(\mathrm{OH})_{2} \mathrm{D}$ were associated with inferior EFS, LSS, and OS in two aggressive NHL subtypes suggests that the prognostic effect of vitamin D may be directly related to its impact on the lymphoma and not simply a general host effect. Biologically, this is plausible, as vitamin $\mathrm{D}$ has been well-documented to be capable of modulating several critical cellular processes, including inhibition of carcinogenesis by induction of cellular differentiation, inhibition of proliferation and angiogenesis, and promotion of apoptosis. ${ }^{5}$ Notably, in vitro vitamin $\mathrm{D}$ has been shown to inhibit proliferation and induce differentiation of both lymphocytes $^{31}$ and lymphoma cell lines. ${ }^{32}$

The associations with OS, but not EFS, which were hinted at in the other NHL subtypes, raise the hypothesis that vitamin D also likely impacts other health outcomes in these diseases with a long natural history, and thereby improves OS. ${ }^{33}$ This will need to be evaluated in larger datasets with sufficient power.

In our study, we measured both the storage form of vitamin $\mathrm{D}$ $[25(\mathrm{OH}) \mathrm{D}]$ and its biologically active metabolite $\left[1,25(\mathrm{OH})_{2} \mathrm{D}\right]$. This examination was prompted by our concern that the low levels of $25(\mathrm{OH}) \mathrm{D}$ found in subjects with worse prognosis might be a function of greater tumor burden with resultant increased 1- $\alpha$-hydroxylase activity, leading to increased conversion of $25(\mathrm{OH}) \mathrm{D}$ to $1,25(\mathrm{OH})_{2} \mathrm{D}$. However, this was not the case. Rather, both lower $25(\mathrm{OH}) \mathrm{D}$ and $1,25(\mathrm{OH})_{2} \mathrm{D}$ levels were associated with inferior EFS and OS. Whether 
Table 3. Multivariable-Adjusted HRs for 1,25-Dihydroxyvitamin D Levels (overall, and stratified by 25-hydroxyvitamin D insufficiency) and Event-Free, Lymphoma-Specific, and Overall Survival

\begin{tabular}{|c|c|c|c|c|c|c|c|c|c|c|c|c|c|}
\hline \multirow[b]{2}{*}{ 1,25-Dihydroxyvitamin D level $(\mathrm{pg} / \mathrm{mL})$} & \multirow[b]{2}{*}{ No. } & \multicolumn{4}{|c|}{ Event-Free Survival } & \multicolumn{4}{|c|}{ Lymphoma-Specific Survival } & \multicolumn{4}{|c|}{ Overall Survival } \\
\hline & & $\begin{array}{l}\text { No. of } \\
\text { Events }\end{array}$ & $\begin{array}{c}\% \\
\text { Events }\end{array}$ & $\mathrm{HR}$ & $95 \% \mathrm{Cl}$ & $\begin{array}{l}\text { No. of } \\
\text { Events }\end{array}$ & $\begin{array}{c}\% \\
\text { Events }\end{array}$ & $\mathrm{HR}$ & $95 \% \mathrm{Cl}$ & $\begin{array}{l}\text { No. of } \\
\text { Events }\end{array}$ & $\begin{array}{c}\% \\
\text { Events }\end{array}$ & $\mathrm{HR}$ & $95 \% \mathrm{Cl}$ \\
\hline \multicolumn{14}{|l|}{ DLBCL, all } \\
\hline $\mathrm{O} 4(62+)$ & 91 & 19 & 20.9 & 1.00 & Reference & 11 & 12.1 & 1.00 & Reference & 12 & 13.2 & 1.00 & Reference \\
\hline Q3 (46-61) & 98 & 35 & 35.7 & 1.86 & 1.06 to 3.26 & 26 & 26.5 & 2.42 & 1.19 to 4.92 & 30 & 30.6 & 2.61 & 1.33 to 5.11 \\
\hline Q2 (34-45) & 86 & 35 & 40.7 & 2.22 & 1.27 to 3.90 & 25 & 29.1 & 2.63 & 1.29 to 5.37 & 28 & 32.6 & 2.73 & 1.38 to 5.40 \\
\hline Q1 $(<34)$ & 92 & 43 & 46.7 & 2.18 & 1.26 to 3.76 & 28 & 30.4 & 2.16 & 1.07 to 4.37 & 30 & 32.6 & 2.14 & 1.09 to 4.21 \\
\hline$P$ for trend & & & & .01 & & & & .10 & & & & .11 & \\
\hline \multicolumn{14}{|l|}{ DLBCL, insufficient 25-hydroxyvitamin D } \\
\hline $\mathrm{Q} 4(62+)$ & 40 & 11 & 27.5 & 1.00 & Reference & 7 & 17.5 & 1.00 & Reference & 8 & 20.0 & 1.00 & Reference \\
\hline Q3 (46-61) & 46 & 19 & 41.3 & 1.74 & 0.83 to 3.65 & 15 & 32.6 & 2.44 & 0.99 to 6.01 & 17 & 37.0 & 2.42 & 1.04 to 5.63 \\
\hline Q2 (34-45) & 50 & 23 & 46.0 & 2.00 & 0.97 to 4.10 & 19 & 38.0 & 2.50 & 1.05 to 5.96 & 21 & 42.0 & 2.44 & 1.08 to 5.53 \\
\hline Q1 $(<34)$ & 54 & 29 & 53.7 & 1.95 & 0.96 to 3.97 & 22 & 40.7 & 1.99 & 0.84 to 4.71 & 23 & 42.6 & 1.88 & 0.83 to 4.26 \\
\hline$P$ for trend & & & & .11 & & & & .33 & & & & .36 & \\
\hline \multicolumn{14}{|l|}{ DLBCL, sufficient 25-hydroxyvitamin D } \\
\hline $\mathrm{Q} 4(62+)$ & 51 & 8 & 15.7 & 1.00 & Reference & 4 & 7.8 & 1.00 & Reference & 4 & 7.8 & 1.00 & Reference \\
\hline O3 (46-61) & 52 & 16 & 30.8 & 2.07 & 0.88 to 4.91 & 11 & 21.1 & 2.81 & 0.88 to 9.02 & 13 & 25.0 & 3.40 & 1.09 to 10.59 \\
\hline O2 (34-45) & 36 & 12 & 33.3 & 2.10 & 0.84 to 5.24 & 6 & 16.7 & 1.77 & 0.47 to 6.64 & 7 & 19.4 & 2.23 & 0.62 to 7.95 \\
\hline Q1 (<34) & 38 & 14 & 36.8 & 2.32 & 0.93 to 5.34 & 6 & 15.8 & 1.66 & 0.47 to 5.93 & 7 & 18.4 & 1.92 & 0.56 to 6.58 \\
\hline$P$ for trend & & & & .17 & & & & .73 & & & & .62 & \\
\hline \multicolumn{14}{|l|}{$\mathrm{TCL}$, all } \\
\hline Median+ $(46+)$ & 36 & 22 & 61.1 & 1.00 & Reference & 11 & 30.6 & 1.00 & Reference & 11 & 30.6 & 1.00 & Reference \\
\hline$<$ median $(<46)$ & 34 & 27 & 79.4 & 1.62 & 0.92 to 2.88 & 17 & 50.0 & 1.83 & 0.86 to 3.93 & 18 & 52.9 & 1.94 & 0.91 to 4.12 \\
\hline$P$ & & & & .09 & & & & .12 & & & & .08 & \\
\hline \multicolumn{14}{|l|}{ TCL, insufficient 25-hydroxyvitamin D } \\
\hline Median + $(46+)$ & 16 & 13 & 81.3 & 1.00 & Reference & 7 & 43.8 & 1.00 & Reference & 7 & 43.8 & 1.00 & Reference \\
\hline$<$ median $(<46)$ & 24 & 20 & 83.3 & 2.07 & 0.93 to 4.62 & 13 & 54.2 & 1.84 & 0.70 to 4.85 & 14 & 58.3 & 1.95 & 0.75 to 5.05 \\
\hline$P$ & & & & .08 & & & & .22 & & & & .17 & \\
\hline \multicolumn{14}{|l|}{ TCL, sufficient 25-hydroxyvitamin D } \\
\hline Median+ $(46+)$ & 20 & 9 & 45.0 & 1.00 & Reference & 4 & 20.0 & 1.00 & Reference & 4 & 20.0 & 1.00 & Reference \\
\hline$<$ median $(<46)$ & 10 & 7 & 70.0 & 1.10 & 0.40 to 3.01 & 4 & 40.0 & 1.82 & 0.45 to 7.36 & 4 & 40.0 & 1.82 & 0.45 to 7.36 \\
\hline$P$ & & & & .86 & & & & .40 & & & & .40 & \\
\hline
\end{tabular}

NOTE. Adjusted for International Prognostic Index. Quartile distribution based on histology specific cut points.

Abbreviations: HR, hazard ratio; DLBCL, diffuse large B-cell lymphoma; Q, quartile; TCL, T-cell lymphoma.

$25(\mathrm{OH}) \mathrm{D}$ exerts biologic effects independent of $1,25(\mathrm{OH})_{2} \mathrm{D}$, or serves merely as a substrate for conversion to $1,25(\mathrm{OH})_{2} \mathrm{D}$ is unclear, although the affinity of $1,25(\mathrm{OH})_{2} \mathrm{D}$ relative to $25(\mathrm{OH}) \mathrm{D}$ for the vitamin $\mathrm{D}$ receptor has been shown to be approximately 650fold greater. $^{34}$

Whether vitamin D supplementation in patients with newly diagnosed lymphoma and 25(OH)D levels below the optimal range will lead to improved outcomes is unknown, but warrants further investigation. The results for TCL, but not DLBCL, suggest supplementation even within the optimal range might be useful. None of the patients were above the optimal range, and there is no justification from our study to consider supraphysiologic levels. Finally, the role of vitamin D supplementation to maintain $25(\mathrm{OH}) \mathrm{D}$ levels within the optimal range for the primary prevention of NHL, which our study did not address, is not known.

In summary, our study provides strong data on the relationship between vitamin D and prognosis in NHL, and suggests a need for additional studies both to confirm our findings and to prospectively assess the role of vitamin D supplementation in NHL progression and survival. At this time, there is no definitive evidence for a causative relationship between lower vitamin D levels and poorer outcomes in lymphoma, and our study did not answer the question of whether normalizing vitamin D levels in these patients improves outcome. We do note that there are general clinical recommendations for vitamin $\mathrm{D}$ testing and replacement in patients with serum 25(OH)D levels below the optimal range. ${ }^{35}$ Our data may provide additional incentive to follow these general guidelines particularly closely in DLBCL and TCL patients.

\section{AUTHORS' DISCLOSURES OF POTENTIAL CONFLICTS} OF INTEREST

The author(s) indicated no potential conflicts of interest.

\section{AUTHOR CONTRIBUTIONS}

Conception and design: Matthew T. Drake, James R. Cerhan Financial support: Matthew T. Drake, James R. Cerhan Administrative support: James R. Cerhan

Provision of study materials or patients: Brian K. Link, Thomas M. Habermann, Stephen M. Ansell, Ivana N. Micallef, William R. Macon, 
Grzegorz S. Nowakowski, David J. Inwards, Patrick B. Johnston, George J. Weiner, Thomas E. Witzig

Collection and assembly of data: Matthew T. Drake, Matthew J. Maurer, Brian K. Link, Thomas M. Habermann, Ravinder J. Singh, Cristine Allmer, James R. Cerhan

Data analysis and interpretation: Matthew T. Drake, Matthew J. Maurer, Cristine Allmer, Susan L. Slager, James R. Cerhan
Manuscript writing: Matthew T. Drake, James R. Cerhan

Final approval of manuscript: Matthew T. Drake, Matthew J.

Maurer, Brian K. Link, Thomas M. Habermann, Stephen M. Ansell, Ivana N. Micallef, Jennifer L. Kelly, William R. Macon, Grzegorz S. Nowakowski, David J. Inwards, Patrick B. Johnston, Ravinder J. Singh, Cristine Allmer, Susan L. Slager, George J. Weiner, Thomas E. Witzig, James R. Cerhan

\section{REFERENCES}

1. Thomas MK, Lloyd-Jones DM, Thadhani RI, et al: Hypovitaminosis $D$ in medical inpatients. N Engl J Med 338:777-783, 1998

2. Holick MF: High prevalence of vitamin D inadequacy and implications for health. Mayo Clin Proc 81:353-373, 2006

3. Holick MF: Vitamin D deficiency. N Engl J Med 357:266-281, 2007

4. Carlberg C: Current understanding of the function of the nuclear vitamin $D$ receptor in response to its natural and synthetic ligands. Recent Results Cancer Res 164:29-42, 2003

5. Bikle D: Nonclassic actions of vitamin D. J Clin Endocrinol Metab 94:26-34, 2009

6. Gorham ED, Garland CF, Garland FC, et al: Vitamin $D$ and prevention of colorectal cancer. $J$ Steroid Biochem Mol Biol 97:179-194, 2005

7. Yin L, Grandi N, Raum E, et al: Meta-analysis: Longitudinal studies of serum vitamin $\mathrm{D}$ and colorectal cancer risk. Aliment Pharmacol Ther 30:113 125, 2009

8. Crew KD, Shane E, Cremers $S$, et al: High prevalence of vitamin $D$ deficiency despite supplementation in premenopausal women with breast cancer undergoing adjuvant chemotherapy. J Clin Oncol 27:2151-2156, 2009

9. Chen $\mathrm{P}, \mathrm{Hu} P$, Xie $D$, et al: Meta-analysis of vitamin $D$, calcium and the prevention of breast cancer. Breast Cancer Res Treat 121:469-477, 2010

10. Kelly JL, Friedberg JW, Calvi LM, et al: Vitamin $D$ and non-Hodgkin lymphoma risk in adults: $A$ review. Cancer Invest 27:942-951, 2009

11. Kricker A, Armstrong BK, Hughes AM, et al: Personal sun exposure and risk of non Hodgkin lymphoma: A pooled analysis from the Interlymph Consortium. Int J Cancer 122:144-154, 2008

12. Giovannucci E, Liu Y, Rimm EB, et al: Prospective study of predictors of vitamin $D$ status and cancer incidence and mortality in men. J Natl Cancer Inst 98:451-459, 2006
13. Lim U, Freedman DM, Hollis BW, et al: A prospective investigation of serum 25-hydroxyvitamin D and risk of lymphoid cancers. Int J Cancer 124:979986, 2009

14. Ng K, Meyerhardt JA, Wu K, et al: Circulating 25-hydroxyvitamin d levels and survival in patients with colorectal cancer. J Clin Oncol 26:2984-2991, 2008

15. Goodwin PJ, Ennis $\mathrm{M}$, Pritchard $\mathrm{Kl}$, et al: Prognostic effects of 25-hydroxyvitamin D levels in early breast cancer. J Clin Oncol 27:3757-3763, 2009

16. Ng AC, Kumar SK, Rajkumar SV, et al: Impact of vitamin $D$ deficiency on the clinical presentation and prognosis of patients with newly diagnosed multiple myeloma. Am J Hematol 84:397-400, 2009

17. Raina $V$, Cunningham $D$, Gilchrist $N$, et al: Alfacalcidol is a nontoxic, effective treatment of follicular small-cleaved cell lymphoma. $\mathrm{Br} \mathrm{J}$ Cancer 63:463-465, 1991

18. Weiner GJ, Witzig TE, Link BK: The University of lowa/Mayo Clinic Lymphoma SPORE: SPORE update. Clin Adv Hematol Oncol 2:57-59, 2004

19. Jaffe ES, Harris NL, Stein $H$, et al: World Health Organization Classification of Tumours: $\mathrm{Pa}$ thology and Genetics, Tumours of Hematopoietic and Lymphoid Tissues. Lyon, France, IARC Press, 2001

20. Habermann TM, Weller EA, Morrison VA, et al: Rituximab-CHOP versus $\mathrm{CHOP}$ alone or with maintenance rituximab in older patients with diffuse large B-cell lymphoma. J Clin Oncol 24:3121-3127, 2006

21. Binkley N, Krueger D, Gemar D, et al: Correlation among 25-hydroxy-vitamin D assays. J Clin Endocrinol Metab 93:1804-1808, 2008

22. Kotsopoulos J, Tworoger SS, Campos $\mathrm{H}$, et al: Reproducibility of plasma and urine biomarkers among premenopausal and postmenopausal women from the Nurses' Health Studies. Cancer Epidemiol Biomarkers Prev 19:938-946, 2010

23. Hofmann JN, Yu K, Horst RL, et al: Long-term variation in serum 25-hydroxyvitamin D concentration among participants in the Prostate, Lung, Colo- rectal, and Ovarian Cancer Screening trial. Cancer Epidemiol Biomarkers Prev 19:927-931, 2010

24. Kaplan EL, Meier P: Nonparametric estimation from incomplete observations. Journal of the American Statistical Association 53:457-481, 1958

25. Cox DR: Regression models and life tables (with discussion). Journal of the Royal Statistical Society B 34:187-220, 1972

26. Shipp MA, Harrington DP, Anderson JR, et al: A predictive model for aggressive non-Hodgkin's Iymphoma: The International Non-Hodgkin's Lymphoma Prognostic Factors Project. N Engl J Med 329:987-994, 1993

27. Solal-Celigny $\mathrm{P}$, Roy $\mathrm{P}$, Colombat $\mathrm{P}$, et al: Follicular lymphoma international prognostic index. Blood 104:1258-1265, 2004

28. Hoster E, Dreyling $M$, Klapper W, et al: A new prognostic index (MIPI) for patients with advancedstage mantle cell lymphoma. Blood 111:558-565, 2008

29. Eilers PH, Marx BD: Flexible smoothing with B-splines and penalties. Stat Sci 11:89-121, 1996

30. Seymour JF, Gagel RF, Hagemeister FB, et al: Calcitriol production in hypercalcemic and normocalcemic patients with non-Hodgkin lymphoma. Ann Intern Med 121:633-640, 1994

31. Provvedini DM, Tsoukas CD, Deftos LJ, et al: 1,25-dihydroxyvitamin D3 receptors in human leukocytes. Science 221:1181-1183, 1983

32. Hickish $T$, Cunningham $D$, Colston $K$, et al: The effect of 1,25-dihydroxyvitamin D3 on lymphoma cell lines and expression of vitamin $D$ receptor in lymphoma. Br J Cancer 68:668-672, 1993

33. Melamed ML, Michos ED, Post $\mathrm{W}$, et al: 25-hydroxyvitamin $D$ levels and the risk of mortality in the general population. Arch Intern Med 168: 1629-1637, 2008

34. Bouillon $\mathrm{R}$, Okamura $\mathrm{WH}$, Norman AW: Structure-function relationships in the vitamin $D$ endocrine system. Endocr Rev 16:200-257, 1995

35. Heaney RP: The vitamin $D$ requirement in health and disease. J Steroid Biochem Mol Biol 97:13-19, 2005 